\title{
Abstract
}

\section{BRCA1 Mutation Analysis in 27 Cypriot Families with High Risk of Hereditary Breast and Ovarian Cancer}

\author{
A. Hadjisavvas ${ }^{1}$, A. Adamou ${ }^{2}$, \\ K.C. Kyriacou ${ }^{1}$ and C. Christodoulou ${ }^{1}$ \\ ${ }^{1}$ The Cyprus Institute of Neurology and \\ Genetics, Nicosia, Cyprus \\ ${ }^{2}$ Oncology Center of Bank of Cyprus, \\ Nicosia, Cyprus
}

In the early 1990's two genes, BRCAl and BRCA2 were discovered that predispose to both breast and ovarian cancers. Although by current estimates only $5-10 \%$ of these cancers are hereditary, the identification of susceptibility genes allows the application of oncogenetics as an alternative method of early detection. Indeed several mutations have been identified in these two genes some of which characterize certain populations, while others are family specific. Population specific mutations might be useful for the screening and the management of familial breast and ovarian cancers.

The incidence of breast and ovarian cancer in Cyprus is estimated at 200 and 40 cases per year respectively. However, there are no genetic data as yet available on the role of these two genes. In an effort to identify possible mutations in our population, we selected 27 families with at least two cases of breast and/or ovarian cancer. Blood was obtained from at least one cancer patient per family and DNA was extracted for mapping mutations in the BRCA1 gene. The methods used included radioactive SSCP analysis and manual direct sequencing which were performed on a group of 49 cases.

So far several mutations have been identified; most of them are located in exons 11, 15, and 16 and in introns 8 and 16. It is of interest that one mutation, which lies in intron 8 , appears to be novel, while the remaining have been reported previously. We are still investigating other possible mutations in BRCA1. 


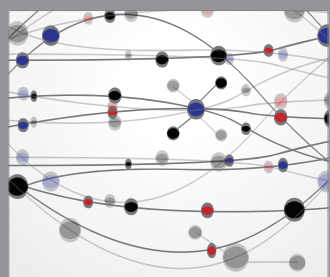

The Scientific World Journal
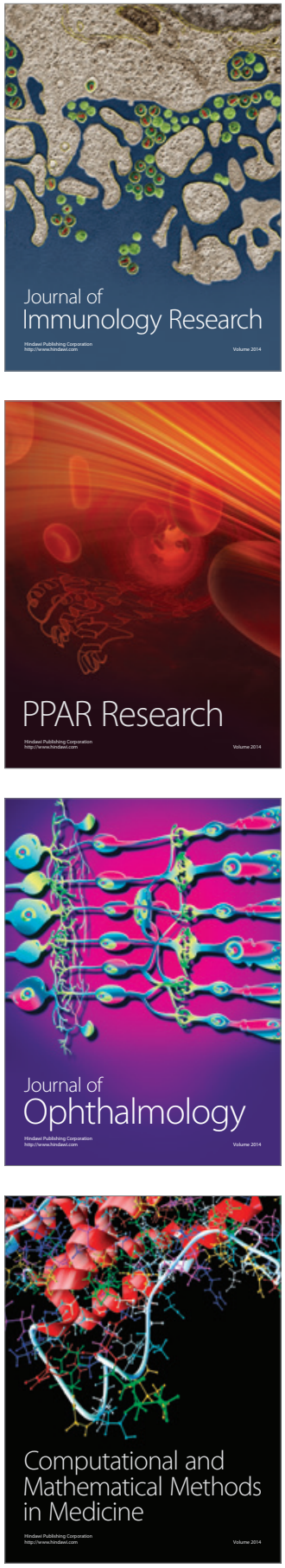

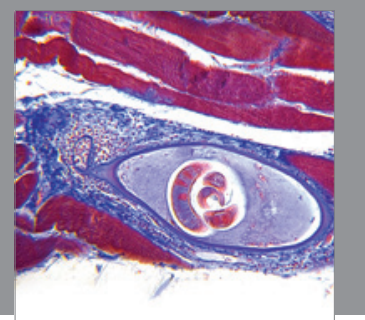

Gastroenterology

Research and Practice
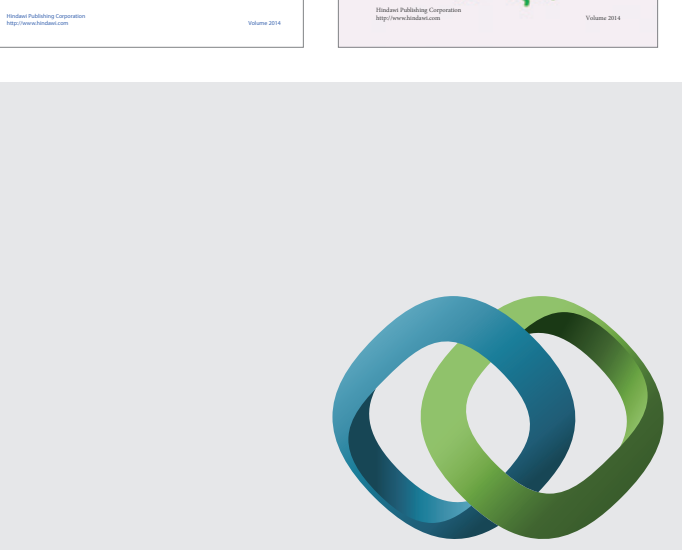

\section{Hindawi}

Submit your manuscripts at

http://www.hindawi.com
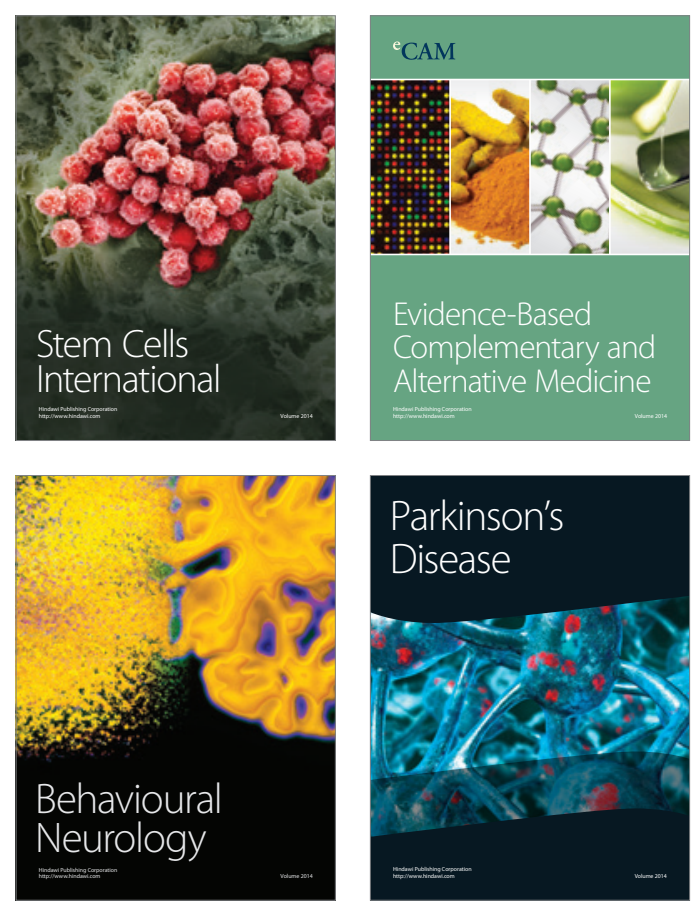

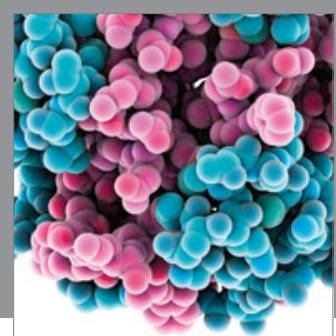

Journal of
Diabetes Research

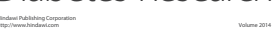

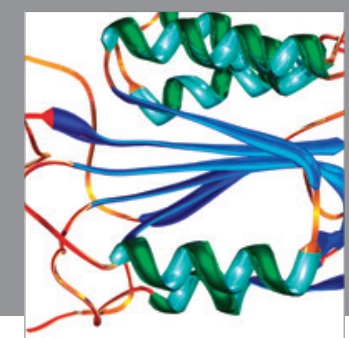

Disease Markers
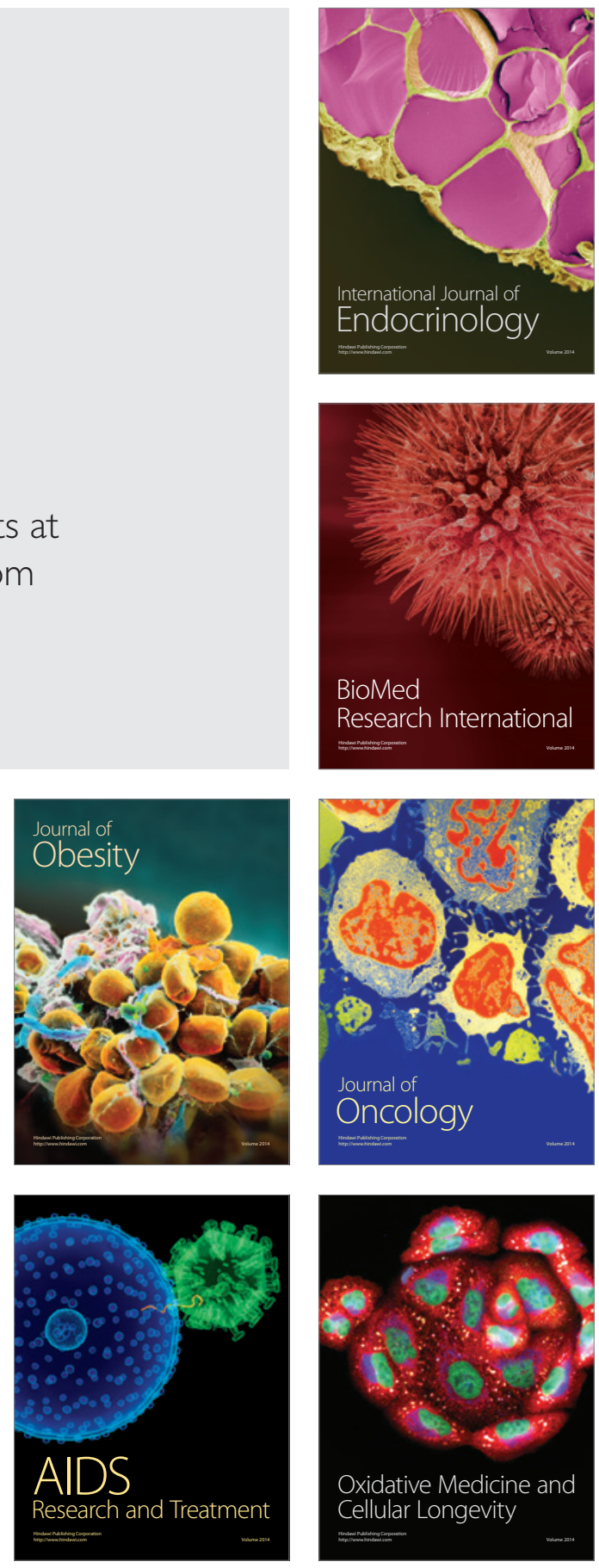